\title{
Bacterially Expressed Rat Retinol-binding Protein is Functional for Retinol and Transthyretin Bindings
}

\author{
Yuji Yamamoto, Tatsuya Yoshizawa, Hiroshi Mano, \\ Shoichi Masushige, and Shigeaki KATO* \\ Department of Agricultural Chemistry, Faculty of Agriculture, \\ Tokyo University of Agriculture, Setagaya-ku, \\ Tokyo 156, Japan
}

(Received September 2, 1995)

\begin{abstract}
Summary Retinol-binding protein (RBP) was expressed in Escherichia coli using the cDNA for rat RBP, and characterized. The expressed $\mathrm{RBP}$ was fused to maltose-binding protein (MBP) at the N-terminal end (MBP-RBP), and MBP was enzymatically removed from the MBP-RBP with proteinase factor $\mathrm{Xa}$. The binding of retinol and transthyretin (TTR) to the recombinant RBP was monitored by means of gel filtration. The recombinant RBP specifically bound to retinol with an affinity similar to that of purified RBP from rat serum. Furthermore, the retinol-bound recombinant RBP formed hetero-complexes with TTR similar to RBP. Thus, the results showed that the recombinant RBP expressed in $E$. coli is as functional as serum RBP in terms of retinol and TTR bindings.
\end{abstract}

Key Words vitamin A, RBP, retinol transport, TTR

Retinol-binding protein ( $\mathrm{RBP}$ ) conveys retinol in blood from the liver to the target organ (for reviews see ref. 1). By binding to RBP, hydrophobic retinol is stabilized and the RBP-retinol complex further forms a hetero-complex with a thyroid hormone binding protein (transthyretin; TTR) in serum (2). The retinol is dissociated from this RBP.TTR hetero-complex and delivered into the target cells. The molecular mechanism of this delivery remains unclear, though it may involve a putative RBP receptor on the cell membrane (3-6), which has not yet been fully characterized.

Rat RBP is a protein with a molecular weight of $21 \mathrm{kDa}(7)$, and is composed of 183 amino acid residues (8). Its three-dimensional structure consists of an $\mathrm{N}$-terminal coil, a $\beta$-sheet core, an $\alpha$-helix and a $\mathrm{C}$-terminal coil. The most unusual feature is an eight-stranded up-and-down $\beta$-barrel core (A to $H)(9)$.

To biochemically analyze the functional domains of RBP during retinol transport, large quantities of RBP are required. In this paper, we report the expression and characterization of recombinant RBP. To simplify the purification

\footnotetext{
* To whom correspondence should be addressed.
} 
procedures, the recombinant RBP was over-expressed as a fusion protein with MBP, which can be purified by means of a single chromatographic separation using amylose resin.

\section{MATERIALS AND METHODS}

Materials. A pMAL-cR1 fusion-expression vector, factor $\mathrm{Xa}$, and antibodies for MBP were obtained from New England Biolabs, Inc. (Beverly, MA, USA).

Construction of Expression Vector. To generate a fusion protein expression system, we constructed a fusion RBP which was linked to a maltose-binding protein (MBP) at the N-terminus. We first generated an expression vector based upon pMAL-cR1 with RBP cDNA obtained by reverse transcription (RT)-polymerase chain reaction (PCR), called pMAL/RBP. Total $\mathrm{cDNAs}$ of rat liver were synthesized from poly(A) ${ }^{+}$RNA with an oligo(dT) primer using AMT reverse transcriptase XL. The full-length of rat RBP cDNA was generated with a pair of oligonucleotides, by means of the PCR (10). The sense primer containing the Eco RI site on the $5^{\prime}$ end was a 26-mer synthetic oligonucleotide (5'-ATGAATTCGAGCGCGACTGCAGGGTG-3') that corresponded to the first $18 \mathrm{bp}$ of the rat RBP sequence, excluding the signal sequence (11). The antisense primer, containing the Xba I site on the $3^{\prime}$ end was a 26-mer synthetic oligonucleotide containing a stop codon on the $3^{\prime}$ end ( $5^{\prime}$-ATTCTAGACTACAAACTGTTTCTTGA-3') that corresponded to bp 535-549 of the rat RBP sequence (11). The PCR product was ligated into the pMAL-cRI vector to generate pMAL/RBP (Fig.1). The

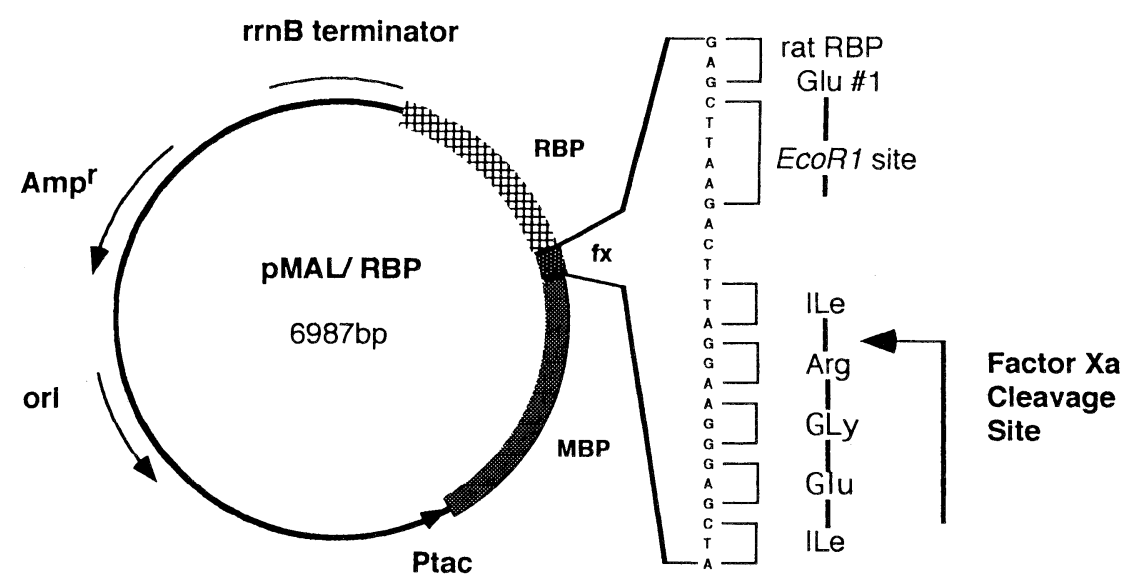

Fig. 1. Expression plasmid for MBP-RBP fusion protein. The arrowheads show the location and direction of the IPTG-inducible tac promoter. The open reading frame for rat $\mathrm{RBP}$ is indicated by the open box. The expansion of the $\mathrm{f} x$ linker details the sequence encoding the endoproteinase factor $\mathrm{Xa}$ recognition sequence (Ile-Glu-Gly-Arg), and the arrow shows the cleavage site for factor $\mathrm{Xa}$ in the linker peptide. 
sequence of rat RBP cDNA was verified by dideoxy sequencing (12).

Recombinant expression in $E$. coli and amylose resin affinity purification of $M B P-R B P$. Transformed TB1 Escherichia coli were cultured overnight in LB media (yeast extract $5 \mathrm{~g}$, tryptone $10 \mathrm{~g}, \mathrm{NaCl} 5 \mathrm{~g} /$ liter $)$ with antibiotics $(100 \mu \mathrm{g} / \mathrm{ml}$ ampicillin) at $37^{\circ} \mathrm{C}$. From this overnight culture, $3 \mathrm{ml}$ aliquots were used to inoculate a 5-liter flask containing 1-liter of LB medium. This flask was then incubated at $37^{\circ} \mathrm{C}$ until the cell density reached an $\mathrm{A}_{550}$ of 0.6 . The culture was then cooled to $30^{\circ} \mathrm{C}$, and isopropylthio-b-galactoside (IPTG) was added at a final concentration of $0.5 \mathrm{mM}$ to induce the RBP fused to the MBP (hereafter designated MBP-RBP). Thereafter, the cultures were incubated at $30^{\circ} \mathrm{C}$ for $2 \mathrm{~h}$. The cells were collected by centrifugation at $4,000 \times g$ and resuspended in a lysis buffer [10 $\mathrm{mm}$ phosphate buffer of $\mathrm{pH} 7.0$ containing $30 \mathrm{~mm} \mathrm{NaCl}, 0.25 \%$-Tween $20,10 \mathrm{~mm}$ $\beta$-mercaptoethanol ( $\beta$-ME), $10 \mathrm{~mm}$ EDTA, and $10 \mathrm{~mm}$ EGTA]. All cell lysis procedures of $E$. coli were performed at $40^{\circ} \mathrm{C}$. The $E$. coli lysate containing MBP-RBP was incubated for $30 \mathrm{~min}$ with $1 \mathrm{mg} / \mathrm{ml}$ of lysozyme, and $\mathrm{NaCl}$ was added up to a final concentratin of $0.5 \mathrm{M}$ in this lysate. This $E$. coli lysate was then centrifuged at $9,000 \times g$ for $30 \mathrm{~min}$. The supernatant was diluted twice with a column buffer [ $10 \mathrm{~mm}$ phosphate, $0.5 \mathrm{M} \mathrm{NaCl}, 1 \mathrm{~mm}$ azide, $10 \mathrm{~mm} \beta$-ME, $1 \mathrm{~mm}$ EGTA] that contained $0.25 \%$ Tween 20 . This sample was then applied to an amylose resin column $(2 \mathrm{~cm} \times 4 \mathrm{~cm})$, which was equilibriated previously with a column buffer containing $0.25 \%$ Tween 20 . The proteins that bound to the resin were then eluted with 2 bed volumes of a column buffer containing $10 \mathrm{~mm}$ maltose.

Purification of recombinant $R B P$. The eluted fraction containing MBP-RBP was concentrated by Centricon-10 (Amicon, Inc., Beverly, MA, USA) to $3 \mathrm{ml}$, and dialyzed against a column buffer containing 0.1\% Triton X-100 (13). This sample, containing MBP-RBP, was then incubated with proteinase factor $\mathrm{Xa}$ at $20^{\circ} \mathrm{C}$ for $3 \mathrm{~h}$ in order to cleave the MBP from MBP-RBP. The cleavaged sample was loaded onto a Sephadex G-75 column $(2.5 \mathrm{~cm} \times 20 \mathrm{~cm})$ that was equilibrated with column buffer, and then eluted with the same buffer. Each fraction was measured for its absorbance at wave length $280 \mathrm{~nm}\left(\mathrm{~A}_{280}\right)$ for protein, and the recombinant RBP was identified by SDS-PAGE analysis. The eluate containing recombinant RBP was concentrated to $3 \mathrm{ml}$ by Centricon-10 (Amicon, Inc.).

Purification of RBP and TTR derived from rat serum. To determine whether this recombinant RBP was as functional as RBP purified from serum, we examined the binding capacities of retinol and TTR to recombinant RBP. Native RBP and TTR were therefore purified from rat serum. All manipulations were performed in a cold room and the protein quantity of each purification step was measured by Lowry method. First, a liter of rat serum (approximately $45 \mathrm{~g}$ protein) was dialyzed against buffer A [0.05 M Tris- $\mathrm{HCl}(\mathrm{pH} 8.5), 0.1 \mathrm{M} \mathrm{NaCl}]$, and the RBP. TTR complex was partially purified by chromatography on a DEAE-Sephadex A-50 column $(5 \mathrm{~cm} \times 30 \mathrm{~cm})$ by elution with a linear $\mathrm{NaCl}$ gradient $(0.1-0.5 \mathrm{M})$. The collected RBP.TTR fraction (approximately $15 \mathrm{~g}$ protein) was dialyzed against buffer $\mathrm{B}[0.05 \mathrm{M}$ Tris- $\mathrm{HCl}(\mathrm{pH} \mathrm{7.0)})$ and applied to a Blue-Sepharose CL- 
$6 \mathrm{~B}$ column $(5 \mathrm{~cm} \times 90 \mathrm{~cm})$ to dissociate RBP and TTR. TTR was collected as the flow-through fraction and RBP was eluted using buffer B containing $2 \mathrm{M} \mathrm{KCl}$. The fractions containing either RBP ( $400 \mathrm{mg}$ protein) or TTR (approximately $9 \mathrm{~g}$ protein) were dialyzed against buffer $\mathrm{C}$ [0.05 $\mathrm{M}$ Tris- $\mathrm{HCl}(\mathrm{pH} 7.0), 0.15 \mathrm{M} \mathrm{NaCl}$, then gel filtrated on a column containing Sephadex G-100 $(2.5 \mathrm{~cm} \times 130 \mathrm{~cm})$, equilibrated with buffer C. RBP was detected by measuring the retinol fluorescence of the fraction (excitation at $330 \mathrm{~nm}$, emission at $460 \mathrm{~nm}$ ) and assayed for the protein at $\mathbf{A}_{280}$. The TTR was also detected at $\mathbf{A}_{280}$. TTR and RBP purity at each stage of the purification was confirmed by SDS-PAGE. Consequently, we obtained purified RBP ( $9 \mathrm{mg}$ protein/liter of rat serum) and TTR (14 mg protein/liter of rat serum) from rat serum. The endogenous retinol bound to the RBP purified from serum, was then removed using organic solvent ( $n$-heptane), as previously reported (14).

Western blot analysis. Rat RBP-specific polyclonal anti-serum was prepared as in a previous report (7). This anti-rat RBP serum cross-reacted specifically to rat RBP in serum by immunodiffusion (data not shown). The proteins were separated by $18 \%$ SDS-PAGE. Proteins in the gel were then transferred to nitrocellulose sheets by electroblotting (15), and immunoreactive proteins with specific antibodies for RBP and MBP (New England Biolabs, Inc.) were visualized by POD Immunostain Set (Wako Pure Chemical Industries, Ltd.).

Retinol binding assay. To assess the binding capacity of recombinant RBP to retinol, recombinant RBP was first incubated with $\left[{ }^{3} \mathrm{H}\right]$ retinol. The purified recombinant $\mathrm{RBP}$ was incubated with $5 \mu \mathrm{Ci}$ of $\left[15-{ }^{3} \mathrm{H}(\mathrm{N})\right] \mathrm{retinol}(37.0 \mathrm{MBq} / \mathrm{ml}$, NEN) overnight in a $125 \mathrm{ml}$ amber Erlenmeyer flask under $\mathrm{N}_{2}$ gas in a cold room. The mixture $\left(27 \times 10^{4}\right.$ d.p.m. $)$ was then applied to a Sephadex G-75 column. Free $\left[{ }^{3} \mathrm{H}\right]$ retinol was removed from the reaction mixture by gel-filtration, that was eluted by buffer $\mathrm{C}$, and the $\left[{ }^{3} \mathrm{H}\right]$ counts in each fraction of the eluate $(2 \mathrm{ml} / 3 \mathrm{ml}$ eluate $)$ were measured using a liquid scintillation counter (ALOKA Co., Ltd. Tokyo).

TTR binding assay. We investigated TTR binding to recombinant RBP. The eluate fraction containing recombinant $\mathrm{RBP} \cdot\left[{ }^{3} \mathrm{H}\right]$ retinol was concentrated to $5 \mathrm{ml}$ by Amicon concentrator/type YM5 filter (W. R. Grace and Co., Danvers, MA, USA), and incubated with a 1.5 fold molar excess of TTR purified from rat serum to form an recombinant RBP $\cdot\left[{ }^{3} \mathrm{H}\right] \mathrm{retinol} \cdot \mathrm{TTR}$ hetero-complex. The mixture was incubated under $\mathrm{N}_{2}$ gas in a cold room overnight. Then, the reaction mixture was eluted through Sephadex G-75 by buffer C. The serum purified RBP and $\left[{ }^{3} \mathrm{H}\right]-$ retinol $\left(\mathrm{RBP} \cdot\left[{ }^{3} \mathrm{H}\right]\right.$ retinol) complex were also obtained by the above method.

\section{RESULTS AND DISCUSSION}

\section{SDS-PAGE analysis and Western blot analysis}

Typical SDS-polyacrylamide gel electrophoresis (SDS-PAGE) profiles from each purification step of recombinant MBP-RBP are shown in Fig. 2. A protein with a molecular weight of about 63,000 was induced only when IPTG was added 


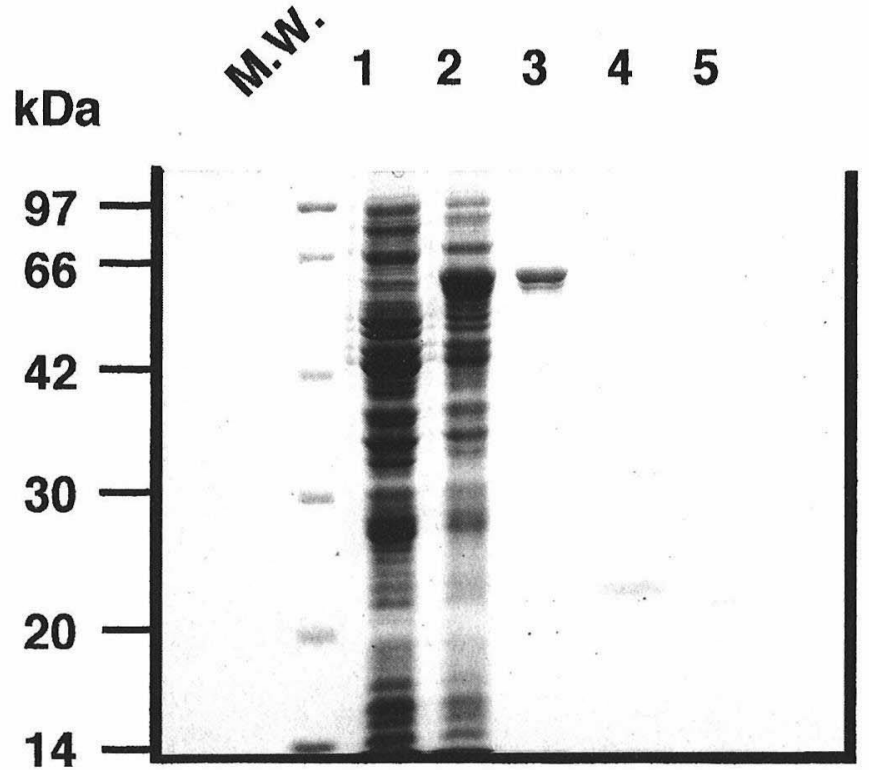

Fig. 2. Purification of MBP-RBP and RBP expressed in E. coli. Purity of the protein was analyzed by electrophoresis on 15\% SDS-PAGE. The proteins were visualized by staining with Coomassie Brilliant Blue. Lane 1, whole cell lysate of transformed $E$. coli not treated with IPTG; Lane 2, whole cell lysate of transformed $E$. coli treated with IPTG; Lane 3, MBP-RBP purified with amylose affinity column; Lane 4, recombinant RBP separated and purified from MBPRBP by factor Xa digestion; Lane 5, serum purified RBP. The molecular marker is shown as M.W.

to the culture medium (see lanes 1 and 2). This protein was purified by amylose resin chromatography (lane 3), then cleaved by factor Xa into two proteins with molecular weights of 21,000 and 42,000 , respectively (data not shown). The cleavage solution was dialyzed against the column buffer and gel filtrated in a column containing Sephadex G-75 $(5 \mathrm{~cm} \times 65 \mathrm{~cm})$, equilibrated with column buffer in order to reduce the free MBP. The slower migration of the RBP protein derived from the MBP-RBP (lane 4) compared with that of the RBP purified from rat serum (lane 5), was observed in the SDS-PAGE analysis. This slow migration of the RBP protein is probably due to the additional 4 amino acids remaining on the $\mathrm{N}$-terminal end after the cleavage with proteinase factor Xa (Fig. 1).

Figure 3 shows the results of Western blots using specific anti-RBP (A) and anti-MBP sera (B). Both anti-sera specifically immunoreacted to the induced proteins even before purification (lane 2 in Fig. 3A and 3B), whereas no specific immunoreaction to the antibodies was observed in the cell lysate of transformed $E$. coli which was not treated with IPTG (lane 1, Fig. 3A and 3B). After digesting MBP-RBP with factor $\mathrm{Xa}$, the anti-RBP serum reacted to the serum RBP as well 

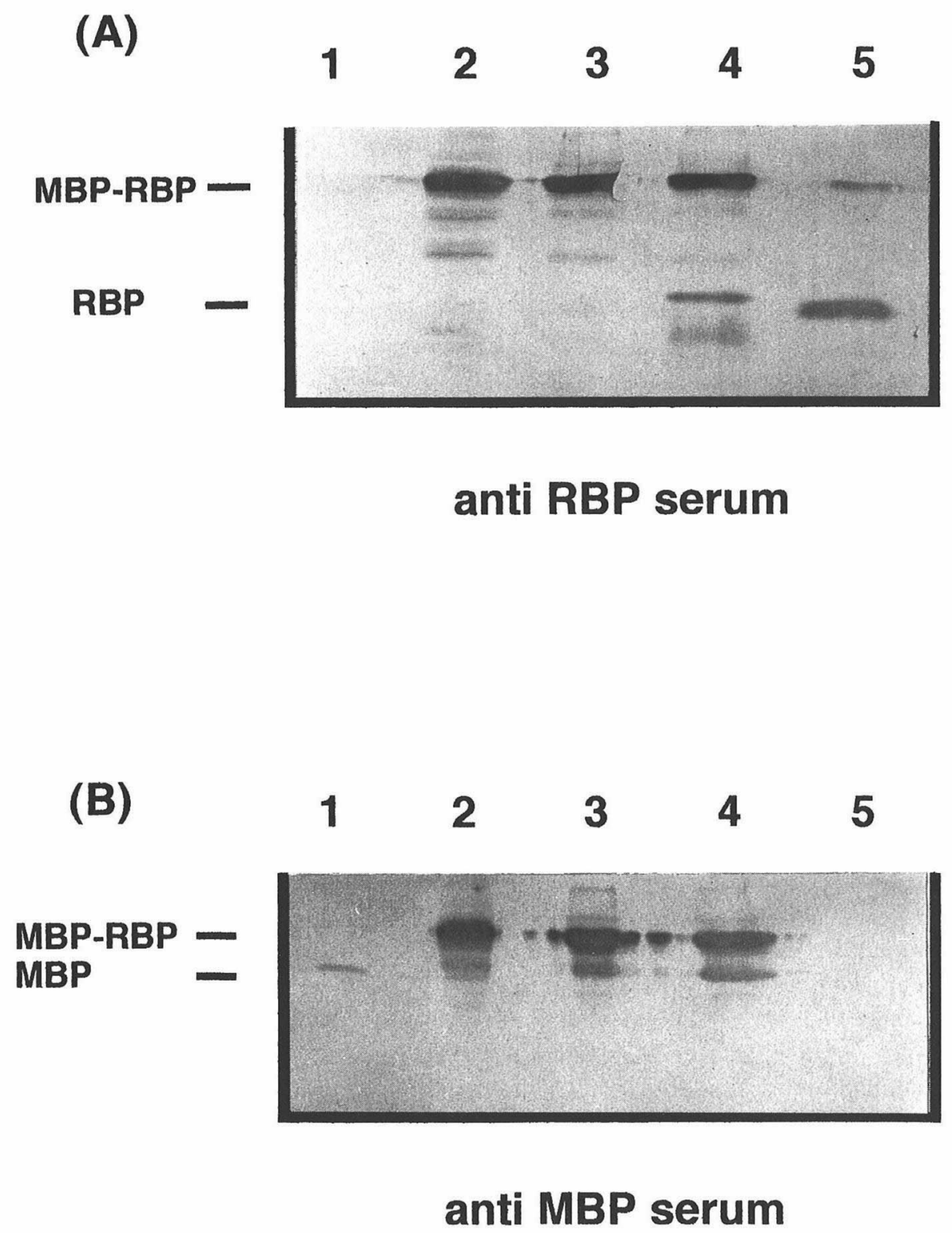

Fig. 3. Western blot analysis of purified MBP-RBP and RBP. The proteins were separated by $18 \%$ SDS-PAGE and transferred to a nitrocellulose membrane. The proteins were analyzed by specific anti-RBP serum (A) or anti-MBP serum (B). Lane 1, whole cell lysate of transformed $E$. coli not treated with IPTG; Lane 2, whole cell lysate of transformed $E$. coli treated with IPTG; Lane 3, MBP-RBP purified with amylose affinity column; Lane 4, RBP separated from MBP-RBP by factor Xa digestion; Lane 5, serum purified RBP. 
as a protein with a molecular weight of 21,000 (lane 4 in Fig. 3A), whereas a protein with a molecular weight of 42,000 specifically reacted only to the anti-MBP serum (lane 4 in Fig. 3B). These results indicate that the induced protein was cleaved into RBP and MBP, by factor Xa.

The results also show that the protein induced by IPTG was a fusion protein of RBP with MBP. The MBP was enzymatically cleaved and removed from MBP-RBP, for further analysis of the recombinant RBP. Furthermore, the yield of recombinant RBP was $200 \mu \mathrm{g}$ from $1.5 \mathrm{~g}$ of supernatant of the MBP-RBP-induced whole cell lysate.

\section{Retinol binding to recombinant $R B P$}

Figure 4 shows the elution profile of recombinant $\mathrm{RBP} \cdot$ retinol complex from the Sephadex G-75 column. We examined the recovered $\left[{ }^{3} \mathrm{H}\right]$ counts during column chromatography. More than $90 \%$ of the added $\left[{ }^{3} \mathrm{H}\right]$ counts was recovered by determining the $\left[{ }^{3} \mathrm{H}\right]$ count accumulation in each fraction (data not shown). To confirm that this binding was retinol-specific, an excess of cold retinol (100 fold molar excess) was added to the reaction mixture. $\left[{ }^{3} \mathrm{H}\right]$-Retinol binding to recom-

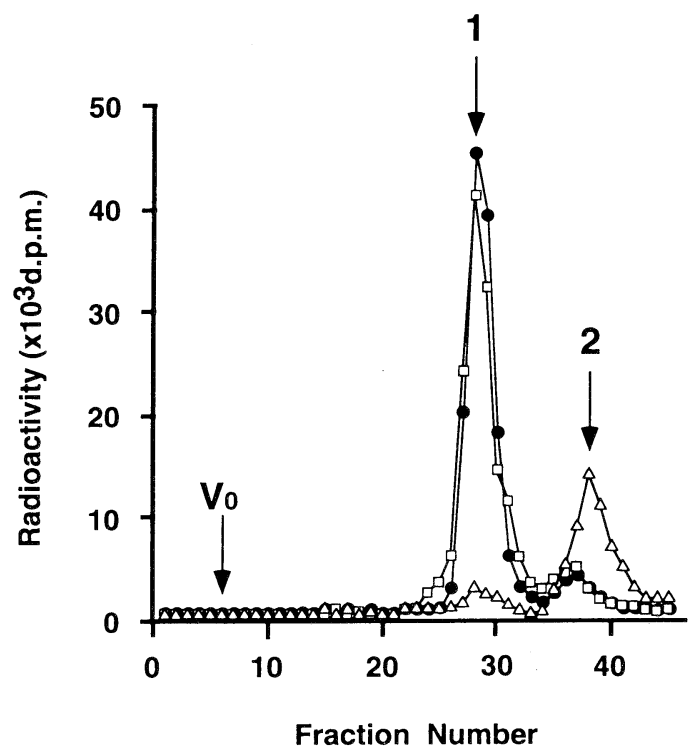

Fig. 4. Retinol binding of recombinant RBP and serum RBP. The recombinant RBP (- $\square$-) or apo-serum RBP (- - ) was incubated with $5 \mu \mathrm{Ci}$ of $\left[{ }^{3} \mathrm{H}\right]$ retinol and was applied to a Sephadex G-75 column equilibrated with buffer $\mathrm{C}$ (see "MATERIALS AND METHODS") to separate free $\left[{ }^{3} \mathrm{H}\right]$ retinol. The binding specificity of retinol to the RBP was determined by incubating recombinant RBP in the presence of 100 fold molar excess of cold retinol $(-\triangle-)$. The arrows in the panel indicates the elution points of void volume [Vo], RBP [1], and free-retinol [2] on the chromatography. 
binant RBP was effectively competed with cold retinol, indicating that the retinol binding was specific. Furthermore, this specific retinol binding capacity was identical between recombinant RBP and the serum RBP, as shown in the figure.

\section{$T T R$ binding to recombinant $R B P$}

The elution profile, represented using $\left[{ }^{3} \mathrm{H}\right]$ counts in the eluates, showed that the serum RBP·retinol formed a hetero-complex with TTR (Fig. 5). The elution profile derived from the mixture of recombinant RBP $\cdot\left[{ }^{3} \mathrm{H}\right]$ retinol and TTR was similar to that of the serum RBP· $\left[{ }^{3} \mathrm{H}\right]$ retinol $\cdot$ TTR hetero-complex (Fig. 5). To examine whether the recombinant RBP had bound to TTR, we checked the existence of free TTR in each collected fraction by means of SDS-PAGE (data not shown). We confirmed that all of the recombinant RBP was bound to TTR. Thus, the ability of recombinant RBP to bind TTR was similar to serum RBP.

In summary, this work describes the production and purification of rat RBP from $E$. coli ( $200 \mu \mathrm{g} \mathrm{RBP/one} \mathrm{liter} \mathrm{culture).} \mathrm{The} \mathrm{recombinant} \mathrm{RBP} \mathrm{was} \mathrm{shown} \mathrm{to}$ be identical to serum RBP by Western blot analysis. The binding capacities of

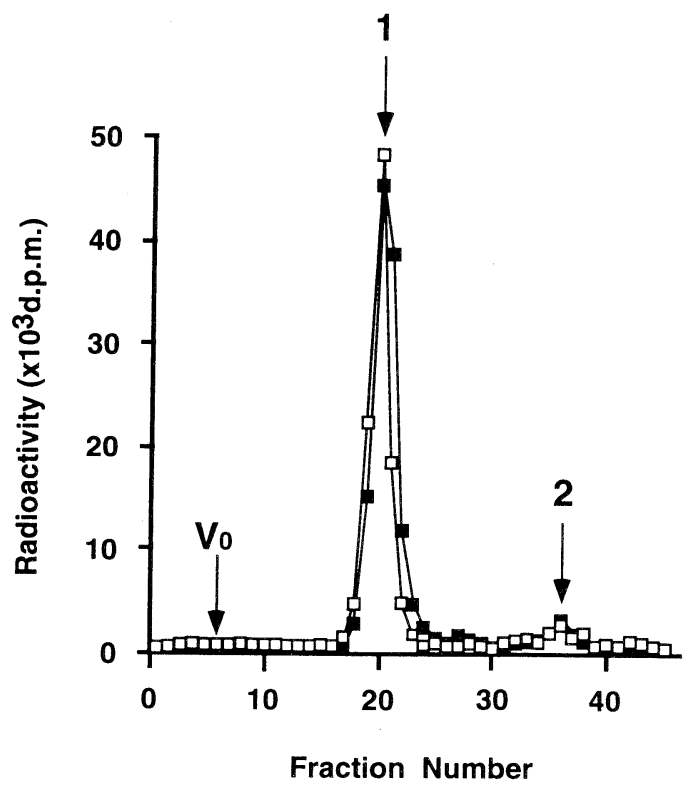

Fig. 5. TTR binding of recombinant RBP and serum RBP. The recombinant RBP $\cdot\left[{ }^{3} \mathrm{H}\right]$ retinol ( $\square-$ ) or serum RBP $\cdot\left[{ }^{3} \mathrm{H}\right]$ retinol (- - ) was incubated with 1.5 fold molar excess of TTR purified from rat serum overnight at $4{ }^{\circ} \mathrm{C}$. Each reaction mixture was applied onto a Sephadex G-75 column equilibrated with buffer C (see "MATERIALS AND METHODS"). The arrows in the panel indicate the elution points of void volume [Vo], RBP.TTR [1] and free-retinol [2] in the chromatography. 
recombinant RBP to retinol and TTR were also found to be identical to serum RBP. Serum RBP has been purified from several mammalian sources $(7,8,16)$, as well as chicken (17), piscine (18) and Xenopus laevis (19). However, due to the paucity of this protein, especially in serum, liters of serum are required to obtain several milligrams of pure protein, in addition, its purification is tedious and costly, which limits the quantities of pure protein available for further studies, such as the protein needed for identification of a cell-membrane RBP receptor. Sivaprasadarao and Findlay (20) previously reported an expression of human RBP in E. coli. In their experiment to purify recombinant RBP using TTR-affinity resin, the cell extract was incubated with retinol. Therefore, in their method, as well as serum RBP recovered from serum sources, the protein is in the retinol-bound form, which makes it difficult to study the physiological roles of apo-RBP. The procedures described here are different from those used by the above authors in purification procedures, and allow quicker and more convenient production of rat RBP in the apo form. It is clear that the apo-RBP obtained by our procedure is more useful for biochemical studies of RBP protein than holo-RBP obtained by other procedures. Moreover, rats rather than human specimens, are more often used as useful specimens of study in many experiments examining the retinol transport mechanism. Therefore, our procedure is a convenient method to obtain RBP from the rat source. Furthermore, in the future, the availability of a large amount of functional recombinant rat RBP obtained by our method will prove useful for experiments such as identification of a putative cell membrane RBP receptor (3-5) which may exist in the target tissues of vitamin A.

\section{REFERENCES}

1) Blomhoff, R., Green, M. H., Berg, T., and Norum, K. R.(1990): Transport and storage of vitamin A. Science, 250, 399-403.

2) Navab, M., Mallia, A. K., Kanda, Y., and Goodman, D. S.(1977): Rat plasma prealbumin. Isolation and partial characterization. J. Biol. Chem., 252, 5100-5106.

3) Heller, J. (1975): Interaction of plasma retinol-binding protein with its receptor: specific binding of bovine and human retinol-binding protein to pigment epithelium cells from bovine eyes. J. Biol. Chem., 250, 3613-3619.

4) Rask, L., and Peterson, P. A. (1976): In vitro uptake of vitamin A from the retinol-binding plasma protein to mucosal epithelial cells from the monkey's small intestine. J. Biol. Chem., 251, 6360-6366.

5) Sivaprasadarao, A., and Findlay, J. B. C. (1988): The interaction of retinol-binding protein with its plasma-membrane receptor. Biochem. J., 255, 561-569.

6) Båvik, C. O., Levy, F., Hellman, U., Wernstedt, C., and Eriksson, U. (1993): The retinal pigment epithelial membrane receptor for plasma retinol-binding protein. Isolation and cDNA cloning of the 63-kDa protein. J. Biol. Chem., 268, 20540-20546.

7) Muto, Y., and Goodman, D. S. (1972): Vitamin A transport in rat plasma. Isolation and characterization or retinol-binding protein. J. Biol. Chem., 247, 2533-2541.

8) Sundelin, J., Laurent, B. C., Anundi, O., Tragardh, L., Larhammar, D., Bjorck, L., 
Eriksson, U., Akerstrom, B., Jones, A., Newcomer, M., Peterson, P. A., and Rask, L. (1985): Amino acid sequence homologies between rabbit, rat, and human serum retinol-binding proteins. J. Biol. Chem., 260, 6472-6480.

9) Newcomer, M. E., Jones, T. A., Åqvist, J., Sundelin, J., Eriksson, U., Rask, L., and Peterson, P. A. (1984): The three-dimensional structure of retinol-binding protein. EMBO J., 3, 1451-1454.

10) Ninomiya, Y., Mochii, M., Eguchi, G., Hasegawa, T., Masushige, S., and Kato, S. (1992): Tissue-specific response of estrogen receptor gene expression to estrogen in chick. Biochem. Biophys. Res. Commun., 187, 1374-1380.

11) Lanrent, B. C., Nilsson, M. H. L., Båvik, C. O., Jones, T. A., Sundelin, J., and Peterson, P. A. (1985): Characterization of the rat retinol-binding protein gene and its comparison to the three-dimensional structure of the protein. J. Biol. Chem., 260, 11476-11480.

12) Sanger, F. S., Nicklen, S., and Coulson, A. R. (1977): DNA sequencing with chain terminating. Proc. Natl. Acad. Sci. USA, 74, 5463-5467.

13) Davie, J. R., Wynn, R. M., Cox, R. P., and Chuang, D. T. (1992): Expression and assembly of a functional E1 component $(\alpha 2 \beta 2)$ of mammalian branched-chain $\alpha$ ketoacid dehydrogenase complex in Escherichia coli. J. Biol. Chem., 267, 16601-16606.

14) Goodman, D. S., and Raz, A. (1972): Extraction and recombinant studies of the interaction of retinol with human plasma retinol-binding protein. J. Lipid Res., 13, 338-347.

15) Towbin, H., Staehelin, T., and Gordon, J. (1979): Electrophoretic transfer of proteins from polyacrylamide gels to nitrocellulose sheets: procedure and some applications. Proc. Natl. Acad. Sci. USA, 76, 4350-4354.

16) Kanai, M., Raz, A., and Goodman, D. S. (1968): Retinol-binding protein: the transport protein for vitamin A in human plasma. J. Clin. Invest., 47, 2025-2044.

17) Mokady, S., and Tal, M. (1974): Isolation and partial characterization of retinolbinding protein from chicken plasma. Biochem. Biophys. Acta, 336, 361-366.

18) Shidoji, Y., and Muto, Y. (1977): Vitamin A transport in plasma of the nonmammalian vertebrates: isolation and partial characterization of piscine retinolbinding protein. J. Lipid Res., 18, 679-691.

19) McKearin, M. D., Barton, M. C., Keller, M. J., and Shapiro, D. J. (1987): Estrogen induces transcription of the Xenopus laevis serum retinol-binding protein gene. J. Biol. Chem., 262, 4939-4942.

20) Sivaprasadarao, A., and Findlay, J. B. C. (1993): Expression of functional human retinol-binding protein in Escherichia coli using a secretion vector. Biochem. J., 296, 209-215. 